\section{Infection Control in Perspective: Infections Due to Medical Equipment and Devices}

The technologic advances in the health care industry in recent years have made the modern hospital a marvel of engineering. Entire generations of medical and nursing students and house officers are being trained in settings where a myriad of medical devices monitor and support bodily functions. The new technology has been a mixed blessing, however, as we identify the associated risks. The Centers for Disease Control have estimated that 850,000 device-related infections occur each year,' and a review of their reports suggests that most of these infections are preventable. Historically, the introduction and widespread use of urinary catheters, ${ }^{2}$ intravenous catheters, ${ }^{3}$ respirators, ${ }^{4}$ arterial monitoring devices, ${ }^{5}$ peritoneal catheters, ${ }^{6}$ and Broviak and Hickman catheters, also have been followed by reports of infection. To reduce the risk of infection with these high-risk devices, recommendations, guidelines, policies and procedures customarily are developed to ensure their proper use, maintenance and timely removal. In addition, industry has responded to this effort by developing disposable devices and/or disposable components to reduce further the risk of infection. However, the unifying theme for prevention and control of infection with devices should be the ongoing education of hospital personnel to increase and sustain awareness of the potential for prevention of devicerelated infections. ${ }^{8}$

Noninvasive devices and equipment, such as thermometers and blood pressure cuffs, appear to constitute a considerably lower risk of infection than invasive devices. While the theoretic possibility of colonization, or even infection, exists with these noninvasive devices, such occurrences have not been well documented. ${ }^{9}$ As infection control practitioners, we are assaulted constantly by a newer and presumably better array of medical products designed to "decrease" or "prevent" nosocomial infection. When competing for the limited number of infection control dollars, it is possible to be lulled into a false sense of security by such promises, while losing sight of the importance of employing proper infection control techniques, including handwashing, ${ }^{10}$ when using these devices.

When compared with invasive medical devices, the role of the hospital environment, including floors, countertops, paper towels, dishes, and toilet paper, is one of the lowest priorities in contributing to infection. However, recent data suggest that routine environmental surveillance still is practiced in many hospitals, ${ }^{1 /}$ despice recommendations to the contrary. ${ }^{12}$ When I co-authored a recent article that mentioned unnecessary environmental surveillance, ${ }^{13}$ we received more than 50 letters and numerous telephone calls, most asking for further information and references, but some adamantly insisting that such practices should be continued. For example, it was difficult, if not impossible, to convince some of the callers that there is no scientific basis for the practice of discarding the unused roll of toilet tissue at the time of the patient's discharge from the hospital, and that the practice should be discontinued.

On pages 315-320 of this issue of Infection Control, Smith et al. report the results of a study of the microbiology of the hospital environment. ${ }^{14}$ In this case, hard plastic probe covers used on electronic thermometers were found to be contaminated with a variety of unknown numbers of pathogenic and non-pathogenic bacteria. Because the probe covers cultured from unopened boxes were sterile, we assume that contamination occurred from the hands of hospital personnel, as the organisms isolated were those commonly found on the hands of most people. The value of studies like this is that they emphasize the importance of the seemingly "old fashioned" and basic infection control techniques in maintaining and caring for all devices used in the care of patients.

Attention to noninvasive devices and various areas of the hospital environment remain lower priorities in terms 
of their direct contribution to nosocomial infection. Until definitive data are available, it would seem reasonable to continue to emphasize the importance of handwashing, good housekeeping techniques, proper handling of equipment, separation of clean and dirty utility areas, and common sense in prevention of colonization and infection due to these lower risk devices and areas. Furthermore, the decision to use disposable dishes, disposable thermometers, or disposable blood pressure cuffs should be based on the needs of an individual institution and not on the putative infection control merits of this equipment. Intravascular catheters, urinary catheters and respirators are well-documented causes of noscomial infection. Items like thermometers and blood pressure cuffs are not.

$$
\begin{array}{r}
\text { William } \bullet \text {. Valenti, M.D. } \\
\text { Infection Control Program } \\
\text { Strong Memorial Hospital } \\
\text { University of Rochester } \\
\text { School of Medicine and Dentistry } \\
\text { Box Med, 601 Elmwood Avenue } \\
\text { Rochester, NY 14642 } \\
\text { (Address reprint requests } \\
\text { to Dr. Valenti.) }
\end{array}
$$

\section{REFERENCES}

1. Stamm WE. Infections due to medical devices. Ann Int Med 1978; 89 (Part 2):764-9.

2. Beeson PB. The case against the catheter. Am J Med 1958; 24:1-3.
3. Bentley DW, Lepper MH. Septicemia due to indwelling venous catheter. JAMA 1968, 206:1749-52.

4. Reinarz JA, Pierce AK, Mays BB, Sanford JP. The potential role of inhalation therapy equipment in nosocomial pulmonary infection. J Clin Invest 1965; 44:831-7.

5. Stamm WE, Colella JJ, Anderson RL, Dixon RE. Indwelling arterial catheters as a source of nosocomial bacteremia. $N$ Engl J Med 1975; 292:1099-1102.

6. Golper T, Bennett W, Jones S. Peritonitis associated with chronic peritoneal dialysis. Dial Transplant 1978; 7:1173-8.

7. Begala J, Maher K, Cherry JD. Risk of catheter-induced sepsis associated with the use of Broviak and Hickman catheters. Abstracts of the 8th Annual Conference of Association for Practitioners in Infection Control, Abstract 18. May 20, 1981, Atlanta, GA.

8. Britt, MR, Schleupner CJ, Matsumiya S. Severity of underlying disease as a predictor of nosocomial infection. JAMA 1978: 238:1047-51.

9. Center for Disease Control. Aseptic handling of thermometers and other equipment for measuring patient temperatures. National Nosocomial Infections Study Report, Annual Summary 1976, published Feb., 1978.

10. Steere AC, Mallison GF. Handwashing practices for the prevention of nosocomial infections. Ann Int Med 1975; 83:683-90.

11. Center for Disease Control. Infection Surveillance and Control Programs in U.S. Hospitals: An Assessment 1976. Morbid Mortal Weekly Report 1978; 27:139-45.

12. American Hospital Association. Statement on microbiologic sampling in the hospital. In: Infection Control in the Hospital, ed 4. Chicago, American Hospital Association, 1979: 183-6.

13. Valenti WM, Sovie MD, Reifler CB, Douglas RG. Cut costs by revising policies and procedures. Hospitals December 1980; 54:84-6.

14. Smith L, Prince HN, Johnson E. Bacteriologic studies on electronic thermometer probes. Infect Control 1981; 2:315-20. 